\title{
Mehr als die Vergangenheit interessiert mich die Zukunft, denn in ihr gedenke ich zu leben ...
}

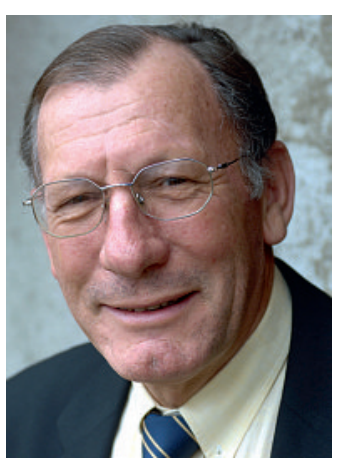

Jean Martin
Das «Time»-Magazin vom 22. März veröffentlichte ein Dossier mit zehn Vorstellungen über die Zukunft. Es ist immer interessant zu sehen, wo wir nach Einschätzung kritischer Beobachter stehen, wohin wir uns bewegen und auf welche Weise wir dies tun werden. In der Folge einige Einsichten. In den vergangenen zehn Jahren erwiesen sich die traditionellen Säulen der Gesellschaft - vom Parlament bis zur Industrie, von der Finanzwelt bis zum Sport und zur katholischen Kirche - in den Vereinigten Staaten und anderswo auf der Welt als korrupt, fehlgeleitet oder inkompetent, sagt Ch. Hayes. Nach Skandalen und Katastrophen liegt der Sozialvertrag in Stücken, unterminiert von Desillusionierung und Verachtung. Ernsthafte Studien zeigen eine feste Korrelation zwischen starken Institutionen, verantwortlich handelnden Eliten und korrekt funktionierenden Volkswirtschaften. Ohne deutlichen Orientierungswandel bewegen wir uns in Richtung Ent-(Unter-)Entwicklung, so die Warnungen. Wer hört sie?

Wir stehen, so R. Salam, «an der Schwelle zur «dropout revolution〉 (Absteiger, Menschen am Rande der Gesellschaft, die nicht mehr mitmachen, Anm. d. Autors). Dies wird eine Ära des Experimentierens mit neuen Lebensarten einläuten.» Verhaltensmuster, die aus Sicht der Mittelklasse irrational erscheinen, können in der Armut vollkommen Sinn machen. Wir werden das Auftauchen eines Archipels von «Kommunen» (Strukturen für ein gemeinschaftliches Leben) und anderen Kooperativen erleben können, die Vater Staat passiven Widerstand bieten, indem sie ihre eigenen Utopien schaffen. Um Steuerabgaben zu vermeiden, werden alternative Währungssysteme und Tauschhandel - begünstigt durch die Informationstechnik - eine Blüte erleben. Wir werden bei der Linken einen neuen Individualismus sehen und die Rechte wird sich immer zynischer und misstrauischer äussern, was den Eindruck vermittelt, als seien wir als Gesellschaft nicht in der Lage, dringende Probleme zu lösen.

Mit typisch amerikanischer Sensibilität weist M. McArdle darauf hin, wie wichtig es ist, die Freiheit des Scheiterns (our cherished freedom to fail) zu wahren. Allerdings müssen wir nach der jüngsten Finanzkrise ein System schaffen, das «besser scheitert», indem wir die Rücklagen der Finanzinstitute erhöhen, den Massnahmenkatalog erweitern, um systemischen Risiken zu begegnen und bessere Mittel vorsehen, um schwer betroffenen Menschen zu helfen.

Zum Klimaproblem: Als Einzelne können wir die fortschreitende Erderwärmung nicht wahrnehmen und müssen uns daher auf jene verlassen, die zuver- lässige wissenschaftliche Messungen vornehmen. Zu einem Zeitpunkt, da wir glaubwürdige Eliten jedoch dringend benötigen würden, wächst die Skepsis.

Ich zähle zu jenen, für die das Fernsehen gelegentlich das Beste und oft das Schlechteste zeigt... Ch. Kenny ist da eher optimistisch. Er geht unter anderem davon aus, dass sich das Fernsehen stark und positiv auf die Stellung der Frau auswirkt. Aus einer in Indien durchgeführten Studie geht hervor, dass Frauen in Haushalten mit Kabelfernsehen eher zum Markt können, ohne dafür die Erlaubnis des Ehemannes einzuholen, Entscheidungen zur Gesundheit der Kinder allein treffen und weniger häufig glauben, dass die Männer das Recht hätten, sie zu schlagen. Sie achten auch nicht so sehr darauf, eher einen Sohn als ein Mädchen zu bekommen. In diesem Zusammenhang ist das grosse demographische Problem in Asien zu bedenken, wo in vielen Gesellschaften Söhne bevorzugt werden. Es fehlen etwa 100 Millionen Mädchen. In seiner Ausgabe vom 6. März 2010 spricht «The Economist» vom Genderzid. Zu viel Fernsehen wird zwar mit Gewaltzunahme, Adipositas und sozialer Isolation assoziiert, doch - so Kenny - es gibt auch positive Auswirkungen: Regierungen werden bescheidener.

Hier einige der getroffenen Vorhersagen bis ins Jahr 2050: Trotz der Rufe nach einer Weltregierung wird uns das nationalstaatliche Modell noch für Jahrzehnte erhalten bleiben. Ein Grossteil der Energie wird weiterhin aus fossilen Brennstoffen gewonnen. Die Kernenergie wird ihren Marktanteil vergrössern. Und - im medizinisch-pflegerischen Bereich - als Folge der verlängerten Lebenserwartung wird die Krankenpflege der grösste Arbeitgeber sein.

Fazit: Wir müssen uns den Normen einer neuen, veränderten Ökonomie anpassen. Hierbei geht es nicht nur darum, den Massstab zu verkleinern, sondern um ein Überdenken unserer gesamten Lebensweise. Eine grosse Herausforderung besteht darin, erneut Vertrauen in die Autorität aufzubauen. Dieses Vertrauen wurde in seinen Grundfesten erschüttert. Dies gilt sowohl für die USA als auch für die Schweiz [1] - jetzt mehr denn je zuvor in den letzten hundert Jahren.

Um mit Clemenceau zu schliessen: «Es ist immer schwierig, Vorhersagen zu treffen, vor allem wenn es um die Zukunft geht.» Woody Allen meint dazu: «Mehr als die Vergangenheit interessiert mich die Zukunft, denn in ihr gedenke ich zu leben.»

Jean Martin, Redaktionsmitglied und Mitglied der Nationalen Ethikkommission
Autorität - heute ein Fremdwort? Schweiz Ärztezeitung. 2009;90(19):784. 